\title{
Serial Sectioning and 3D-reconstruction of Ferrite Allotriomorphs Nucleated at Grain Boundary Faces in an Fe-C-Mn Alloy
}

\author{
L. CHENG $^{1)}$ Z. G. LI $^{2)}$ and K. M. WU ${ }^{1)}$ \\ 1) Key Laboratory for Ferrous Metallurgy and Resources Utilization of Ministry of Education, Department of Applied Physics, \\ Wuhan University of Science and Technology, Wuhan 430081, China. E-mail: wukaiming@wust.edu.cn \\ 2) Technology Center, Baoshan Iron and Steel Co. Ltd., Shanghai, 201900, China.
}

(Received on January 18, 2008; accepted on March 3, 2008)

\begin{abstract}
Three-dimensional morphology of ferrite allotriomorphs nucleated at grain boundary faces in an $\mathrm{Fe}-0.09 \% \mathrm{C}-1.48 \% \mathrm{Mn}$ alloy was revealed by means of serial sectioning in conjunction with computer-aided three-dimensional reconstruction techniques. Ferrite allotriomorphs formed at grain boundary faces appeared to be oblate ellipsoids on usual two-dimensional planar sections. Three-dimensional reconstruction shows that they were large in one dimension, specifically in the depth direction of specimens in this study, some of them being approximately prolate ellipsoids rather than an equiaxed pancake shape as usually assumed.
\end{abstract}

KEY WORDS: steels; microstructure; ferrite; three-dimensional morphology.

\section{Introduction}

Steels are by far the most economical and recyclable metals in engineering material family. Grain boundary ferrite allotriomorphs are the first product of the diffusional decomposition of austenite at most austenite grain boundaries in plain carbon and in many alloy steels during isothermal reaction and continuous cooling. They have a significant influence on the hardenability and mechanical properties of low and medium carbon steels. The influence of precipitate morphology on mechanical properties is well established. ${ }^{1)}$ Competitive formation of grain boundary ferrite allotriomorphs and intragranularly nucleated ferrite has a strong effect on the mechanical properties of steel weldments and grain refinement of commercial steels. ${ }^{2,3)}$ The mechanical properties are thus strongly associated with the nucleation, growth and morphology of ferrite allotriomorphs.

The three-dimensional features of microstructure play an essential role for understanding of the transformation behavior and properties of microstructure. Growth models of grain boundary precipitates based upon assumed three-dimensional (3D) morphologies of precipitates in the past decades. ${ }^{4,5)}$ Few studies are conducted on the 3D morphology of ferrite allotriomorphs nucleated at grain boundary faces. The investigation on grain refinement and growth kinetics of grain boundary ferrite allotriomorphs in precise correlation with their morphologies is yet to be made.

The common practice on morphological observation is to examine two-dimensional (2D) planar sections of a material microstructure. With the progress of instrumentation and computer science, 3D characterization, quantification, and representation of materials structure has become a useful approach to understand microstructures and phase transformation. 3D analysis and characterization were made from nanometer-size precipitates by means of atom probe ${ }^{6)}$ and X-ray crystal microscope, ${ }^{7)}$ to millimeter-size grains by means of focused ion-beam tomography ${ }^{8)}$ and optical microscope. $^{9-14)}$ In this study, three-dimensional analysis is made to understand morphological features of ferrite allotriomorphs nucleated at austenite grain boundary faces in a low carbon $\mathrm{Fe}-\mathrm{C}-\mathrm{Mn}$ alloy.

\section{Experimental Procedures}

The alloy was prepared by vacuum induction melting utilizing high purity electrolytic iron, graphite and manganese. The chemical composition of the alloy is shown in Table $\mathbf{1 .}$ A $50 \mathrm{~kg}$ ingot of the alloy was hot rolled to a plate of $50 \mathrm{~mm}$ thickness at $1000^{\circ} \mathrm{C}$ and subsequently, the slab was cold rolled by $70 \%$. Specimens, $10 \times 10 \times 0.35 \mathrm{~mm}$ in size, were austenitized at $1250^{\circ} \mathrm{C}$ under a purified argon atmosphere and isothermally reacted in a salt bath at $690^{\circ} \mathrm{C}$ and

Table 1. Chemical composition of the alloy.

\begin{tabular}{cc}
\hline Element & Mass\% \\
\hline $\mathrm{C}$ & 0.09 \\
$\mathrm{Mn}$ & 1.48 \\
$\mathrm{Si}$ & 0.20 \\
$\mathrm{Al}$ & 0.01 \\
$\mathrm{~V}$ & 0.05 \\
$\mathrm{Fe}$ & Balance \\
\hline
\end{tabular}


swiftly quenched into iced brine.

Specimens were polished with an automatic grinder polisher-Buehler Minimet1000 — under a fixed polishing load and time. The polished surface of each layer was slightly etched with $3 \%$ nital. Fiducial hardness indents, for the purpose of alignment and determination of image size, were applied using a hardness tester with a Vickers hardness indenter at a $100 \mathrm{~g}$ load. The thickness of a removed layer was calculated from the known ratio of indenter diagonal to depth by measuring diagonal length of the hardness indents before and after each polishing. Approximately $0.41 \pm 0.09 \mu \mathrm{m}$ was repeatedly polished away using a Texmet polishing cloths in this work. Once the polishing, etching and hardness indenting were completed, a series of digital optical micrographs were obtained at a magnification of 200. The digital images were aligned and processed by Scion Image and Adobe Photoshop, respectively. The images were transferred into a volume data set by ImgToVol, and then was visualized using AVS software.

\section{Results and Discussion}

\subsection{Optical Micrographs of Ferrite Allotriomorphs}

Grain boundary allotriomorphs are crystals that nucleate at grain boundaries of the matrix phase and grow preferentially with more or less smooth interface. ${ }^{15)}$ As the first phase forming on prior austenite grain boundaries during cooling below $\mathrm{A}_{\mathrm{e} 3}$, ferrite allotriomorphs nucleate first at grain corners ${ }^{16)}$ and then successively at austenite edges and faces. ${ }^{17,18)}$ A typical optical micrograph of ferrite allotriomorphs formed in the specimen reacted at $690^{\circ} \mathrm{C}$ for $15 \mathrm{~s}$ is shown in Fig. 1. The ferrite grains indicated by thin arrows are allotriomorphs nucleated at grain boundary faces, and the ferrite grain indicated by a thick arrow is an allotriomorph nucleated at grain boundary edge, i.e. the triple point of grain boundaries on 2D sections. Based on observations on $2 \mathrm{D}$ sections, face-nucleated ferrite grains are better described to be elongated allotriomorphs.

\subsection{D-reconstructed Visulization of Ferrite Allotri- omorphs}

Figure 2 shows a 3D-reconstructed image of a ferrite allotriomorph nucleated at a grain boundary face. It is seen that the ferrite allotriomorph is long in one dimension, and small in the other two dimensions. It does not exhibit an equiaxed pancake shape along the austenite grain face as is usually assumed. ${ }^{19-21)}$ The aspect ratio (width/length) of this ferrite allotriomorph is smaller than $\sim 1 / 5$, not consistent with ferrite allotriomorphs in $\mathrm{Fe}-\mathrm{C}$ alloy ${ }^{19)}$ and $\mathrm{Fe}-\mathrm{C}-\mathrm{X}$ alloy ${ }^{20)}$ with a typical aspect ratio approximately $1 / 3$ based on measurement on $2 \mathrm{D}$ sections. In this study, it was found that the 3D-reconstructed ferrite allotriomorphs formed at grain boundary faces are elongated in one direction with smaller aspect ratio, rather than being oblate ellipsoids. The reason is yet to be clarified.

Although the shape of a face-nucleated allotriomorph is often approximated by an oblate ellipsoid, ${ }^{21)}$ elongated allotriomorphs that would be better approximated by a prolate ellipsoid were copiously observed by breaking the specimen along the prior austenite boundary. ${ }^{22)}$ Spanos and $\mathrm{Kral}^{23,24)}$ also found that 3D shape of the ferrite precipitates

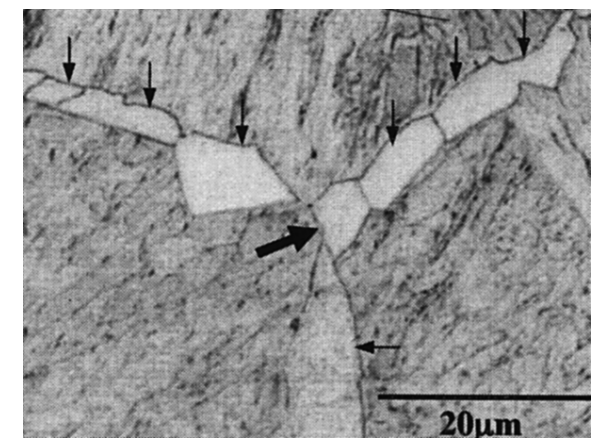

Fig. 1. Optical micrograph of ferrite allotriomorphs formed at an austenite grain boundary edge (indicated by a thick arrow) and faces (indicated by thin arrows) in the specimen isothermally reacted at $690^{\circ} \mathrm{C}$ for $15 \mathrm{~s}$.

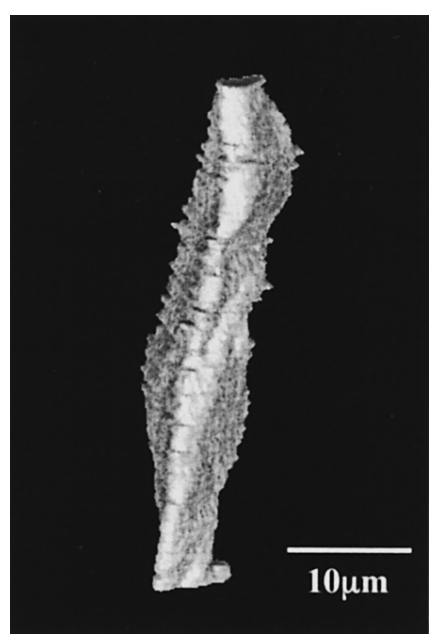

Fig. 2. 3D-Reconstructed image of a ferrite allotriomorph formed at an austenite grain boundary face.

along an austenite boundary in an $\mathrm{Fe}-\mathrm{C}-\mathrm{Ni}$ alloy is actually a spike or elongated pyramid. Their morphology is quite different from the shape called as Widmanstätten ferrite sideplate, on 2D polished sections.

In Fig. 3 are shown different views of 3D-reconstructed ferrite allotriomorphs which grew along a nearly straight austenite grain boundary in the specimen isothermally reacted at $690^{\circ} \mathrm{C}$ for $10 \mathrm{~s}$. They were reconstructed by totally 134 serial sections. Figure 3(a) is the view from the top section and Fig. 3(b) from the bottom section. All of ferrite grains were long in one dimension and arranged nearly parallel to each other. This is different from cementite, reported by Kral and Spanos, ${ }^{25)}$ which only has two fundamental morphologies: dendritic grain boundary precipitates and Widmanstätten precipitates. According to $3 \mathrm{D}$ reconstruction, it was discovered that some of ferrite grains were impinged against each other. They tended to coalesce to cover the grain boundary face.

Figure 4 shows the rotated view of a 3D-reconstructed image of a large ferrite grain indicated by white thick arrows in Fig. 3. It appears that this large ferrite grain might be formed by the impingement and coalescence of two or three grains during their growth, indicated by white thin arrows in Fig. 4. The serial sectioning (Fig. 5) also showed that the large ferrite grain, indicated by black thin arrows in Fig. 5, might consist of two or three small grains. It is likely 

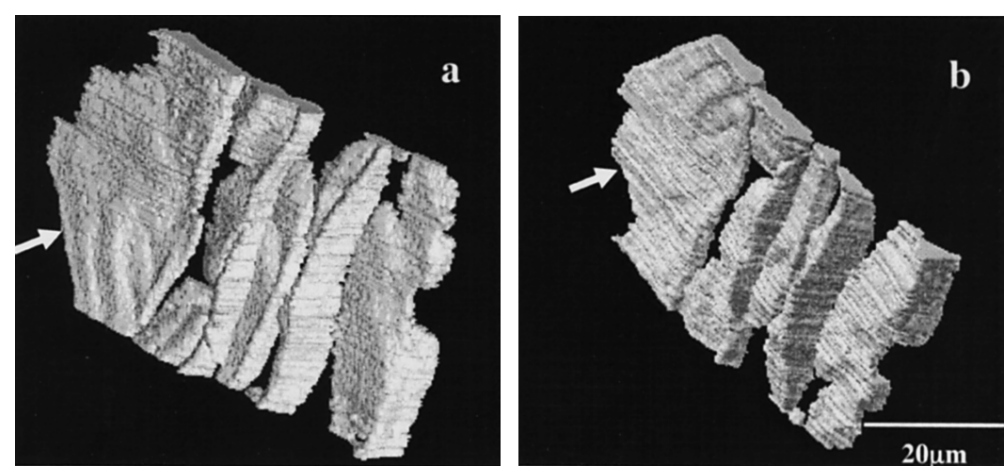

Fig. 3. Different views from the top (a) and bottom (b) sections of 3D-reconstructed ferrite allotriomorphs in the specimen isothermally reacted at $690^{\circ} \mathrm{C}$ for $10 \mathrm{~s}$.

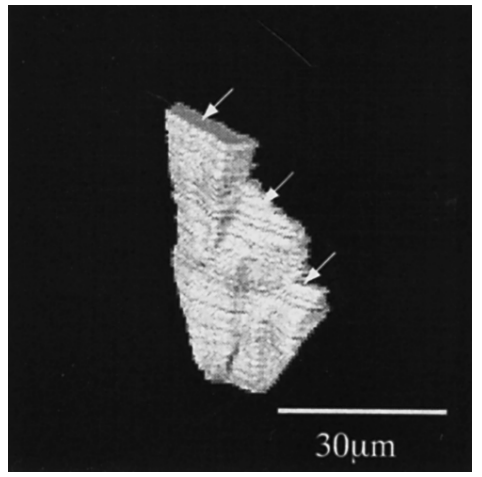

Fig. 4. A rotated view of the ferrite allotriomorph indicated by white thick arrows in Fig. 3.

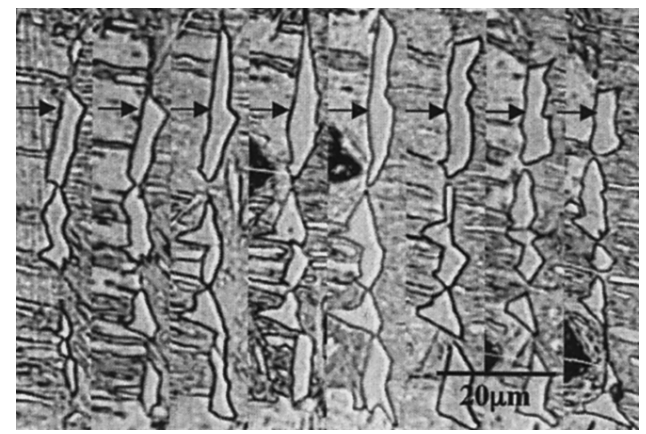

Fig. 5. Eight serial sections spaced $8.2 \mu \mathrm{m}$ apart in depth; i.e., every 20th section from a large portion of $2 \mathrm{D}$ stack for the 3D-reconstruction of Fig. 3.

that, at earlier stages of growth, ferrite allotriomorphs might predominantly grow along the grain boundary owing to less soft and hard impingement; at later stage of growth, ferrite allotriomorphs tended to impinge against each other and coalesce with adjacent allotriomorphs. This would be similar to the growth of acicular ferrite formed at intragranular inclusions. ${ }^{26)}$ The acicular ferrite lengthens very fast at earlier stages of transformation in the austenite matrix, then widens slowly at later stages of transformation.

\subsection{Serial Sectioning and 3D Analysis of Ferrite Al- lotriomorphs}

Figure 5 shows eight serial sections spaced $8.2 \mu \mathrm{m}$ apart in depth; i.e., every 20th section from a large portion of 2D stack for the 3D-reconstruction of Fig. 3. In Fig. 5(a) it is seen that five allotriomorphs are formed along a grain boundary. Two of them appeared to be elongated allotriomorphs on this 2D section. As serial sectioning proceeded, one grain disappeared and four grains were remained in Fig. 5(b). In Fig. 5(c), it is evident that some protuberances were located on one side of some of the ferrite allotriomorphs, the other side remaining relatively planar.

Figure 6 shows the optical micrographs and 3D images reconstructed by totally 127 serial sections, of ferrite allotriomorphs formed at grain boundary faces and edges in a part of a whole austenite grain in the specimen isothermally reacted at $690^{\circ} \mathrm{C}$ for $10 \mathrm{~s}$. Figures $6(\mathrm{a})-6(\mathrm{c})$ show the top, the 12th and the bottom section, respectively. The allotriomorphs indicated by black thin arrows in Figs. 6(a) and 6 (b) were elongated and triangle on these 2D sections. 3Dreconstructed images revealed that both the elongated and triangle allotriomorphs, indicated by white triangle arrows, were large in one dimension, as shown in Figs. 6(d) and 6(e).

In Fig. 6(b), it is seen that a ferrite allotriomorph formed at a triple point, indicated by a black thick arrow, grew into grain interior. Serial sectioning demonstrated that it was subsequently impinged and coalesced with ferrite allotriomorphs appeared in the followed sections, which grew from three different grain boundary faces. It is shown in Fig. 6(e) that the ferrite allotriomorph formed at the triple point is connected with the ferrite allotriomorphs nucleated at grain boundary faces, indicated by three white thin arrows.

Like ferrite grains nucleated at an individual nearly straight grain boundary, the ferrite allotriomorphs formed at a whole austenite grain boundary elongated along similar directions, tended to cover the whole grain boundary. This may indicate that the allotriomorphs keep a certain orientation relationship with the austenite grains. As shown in Fig 6(e) the two small grains, labelled by two thick arrows are elongated along a direction different from others and parallel to each other. They appeared to be different shape on 2D sections. They grew into interior of austenite grain and did not elongate along grain boundary on the polished plane.

Several decades ago, on the basis of many two-dimensional (2D) optical micrographs, Dubé ${ }^{21)}$ developed a classification system for the different morphologies of precipitates in steels. According to this classification system, grain boundary allotriomorphs are formed at matrix grain boundaries and are often described as two abutting spherical caps, or usually described as an oblate ellipsoid in two dimen- 

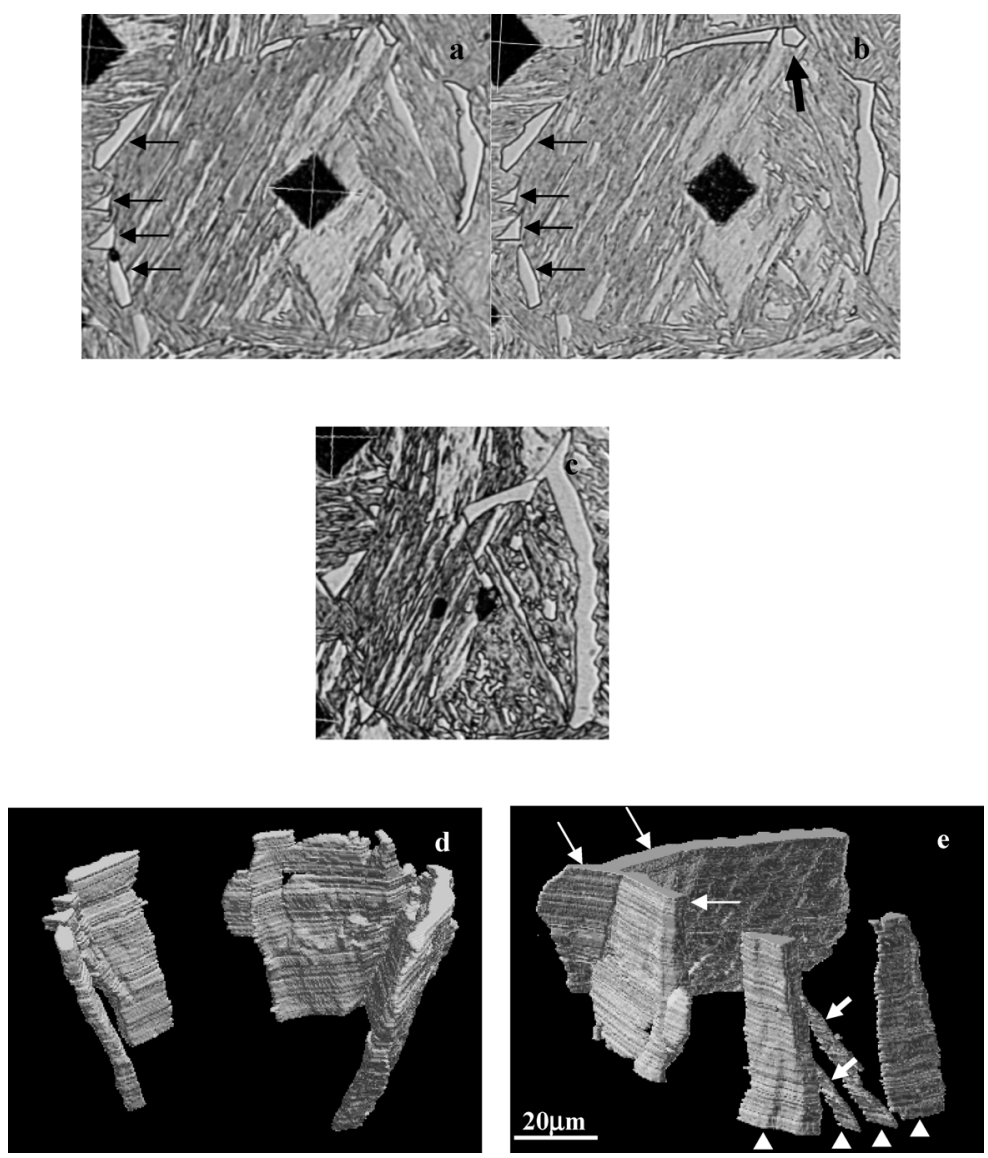

Fig. 6. (a), (b) and (c) optical micrographs, and (d) and (e) 3D-reconstructed images viewed from the top and bottom sections, respectively, of ferrite allotriomorphs formed at the boundaries of a whole austenite grain in the specimen isothermally reacted at $690^{\circ} \mathrm{C}$ for $10 \mathrm{~s}$.

sions. ${ }^{19)}$ Recently, Thewlis ${ }^{27)}$ made a review on the classification and quantification of microstructures in steels. In this literature, prior austenite grain boundary primary ferrite allotriomorphs are usually observed in the form of polygonal grains or veins. In this study, it is seen in Figs. 2-6 that the morphology of face-nucleated allotriomorphs varied considerably from one grain to another, even on the same grain boundary face. In some cases the ferrite allotriomorph was relatively smooth and elongated and in others was sufficiently angular. However, 3D-reconstruction revealed that angular allotriomorphs and most of smooth and elongated allotriomorphs are oriented essentially in one direction and usually large in this direction. In this sense, the elongated and angular allotriomorphs are similar. The large elongated ferrite allotriomorphs might be impinged and coalesced with small smooth and/or angular allotriomorphs during their growth. Some of face-nucleated ferrite allotriomorphs appeared to be more like prolate ellipsoids instead of exhibiting an equiaxed pancake shape along the grain boundary face as is usually assumed.

\section{Summary}

Three-dimensional morphology of allotriomorphs formed at grain boundary faces in an $\mathrm{Fe}-0.09 \% \mathrm{C}-1.48 \% \mathrm{Mn}$ alloy was revealed utilizing serial sectioning in conjunction with computer-aided reconstruction. The morphology of facenucleated allotriomorphs varied considerably from one grain to another, even on the same grain boundary face.
Some of face-nucleated ferrite allotriomorphs appeared to be large in one dimension and be prolate ellipsoids rather than exhibiting an equiaxed pancake shape along the grain boundary faces as usually assumed. In this research, ferrite allotriomorphs were developed for a longer time. Some of them started to impinge against each other. In order to study morphology of ferrite allotriomorphs, specimens with shorter holding times are to be investigated.

\section{Acknowledgements}

The authors gratefully acknowledge the support from NSFC (National Natural Science Foundation of China) and Baosteel under the Grant No. 50734004, and Scientific Research Foundation for the Returned Overseas Chinese Scholars, State Education Ministry of China. The authors are thankful to Dr. Enomoto, Ibaraki University, Japan, for valuable discussion as well as reviewing the manuscript.

\section{REFERENCES}

1) G. E. Dieter: Mechanical Metallurgy, McGraw-Hill, New York, (1961), 137.

2) S. J. Jones and H. K. D. H. Badeshia: Metall. Mater. Trans. A, 28A (1997), 2005.

3) K. M. Wu, T. Yokomizo and M. Enomoto: ISIJ Int., 42 (2002), 1144.

4) H. B. Aaron and H. I. Aaronson: Acta Metall., 16 (1968), 789.

5) J. R. Bradley and H. I. Aaronson: Metall. Trans. A, 8A (1977), 317.

6) M. Peet, S. S. Babu, M. K. Miller and H. K. D. H. Bhadeshia: Scr. Mater, 50 (2004), 1277.

7) W. Liu, G. E. Ice, B. C. Larson, W. Yang, J. Z. Tischler and J. D. Budai: Metall. Mater. Trans. A, 35A (2004), 1963. 
ISIJ International, Vol. 48 (2008), No. 6

8) A. J. Kubis, G. J. Shiflet, D. N. Dunn and R. Hull: Metall. Mater. Trans. A, 35A (2004), 1935.

9) C. Zhang, A. Suzuki, T. Ishimaru and M. Enomoto: Metall. Mater. Trans. A, 35A (2004), 1927.

10) T. Yokomizo, M. Enomoto, O. Umezawa, G. Spanos and R. O. Rosenberg: Mater. Sci. Eng. A, 344A (2003), 261.

11) N. Chawla, V. V. Ganesh and B. Wunsch: Scr. Mater., 51 (2004), 161

12) R. E. Hackenberg, D. P. Nordstrom and G. J. Shiflet: Scr. Mater., 47 (2002), 357.

13) K. M. Wu and M. Enomoto: Scr. Mater., 46 (2002), 569.

14) K. M. Wu: Scr. Mater, 54 (2005), 569.

15) V. F. Zackay and H. I. Aaronson: Decomposition of Austenite by Diffusional Processes, Interscience, New York, (1962), 387.

16) W. Huang and M. Hillert: Metall. Mater. Trans. A, 27A (1996), 480.

17) W. F. Lange, III, M. Enomoto and H. I. Aaronson: Metall. Trans. A, 10A (1979), 1951.

18) W. F. Lange, III, M. Enomoto and H. I. Aaronson: Metall. Trans. A, 19A (1988), 427.
19) J. R. Bradley, J. M. Rigsbee and H. I. Aaronson: Metall. Trans. A, 8A (1977), 323.

20) J. R. Bradley and H. I. Aaronson: Metall. Trans. A, 12A (1981), 1729 .

21) C. A. Dubé, H. I. Aaronson and R. F. Mehl: Rev. Metall., 55 (1958), 201.

22) M. Enomoto, W. F. Lange, III and H. I. Aaronson: Metall. Trans. A, 17A (1986), 1399.

23) G. Spanos and M. V. Kral: Proc. Int. Conf. on Solid-Solid Phase Transformations '99, ed. by M. Koiwa, K. Otsuka and T. Miyazaki, The Japan Institute of Metals, Sendai, Japan, (1999), 1469.

24) M. V. Kral and G. Spanos: Metall. Mater. Trans. A, 36A (2005), 1199.

25) M. V. Kral and G. Spanos: Acta Mater, 47 (1999), 711.

26) M. Enomoto, K. M. Wu, Y. Inagawa, T. Murakami and S. Nanba: ISIJ Int., 45 (2005), 756.

27) G. Thewlis: Mater. Sci. Technol., 20 (2004), 143. 